УДК 327(73:497.1)“197“(093.2)

321.74:929 Тито

Dr Dragan BOGETIĆ

Institut za savremenu istoriju

\title{
AMERIČKE ANALIZE BUDUĆNOSTI JUGOSLAVIJE POSLE TITA S POČETKA 70-IH GODINA*
}

\begin{abstract}
APSTRAKT: $U$ radu su obrađena kolebanja $i$ dileme američke vlade $u$ vezi sa političkom strategijom prema Jugoslaviji u situaciji kada se javljaju ozbiljne dileme o sudbini te zemlje posle Titove smrti. S obzirom na jačanje centrifugalnih sila u Jugoslaviji, politički krugovi u SAD-u postaju sve više skeptični po pitanju opstanka jugoslovenske federacije i skloni preduzimanju određenih mera kojima bi se osujetile eventualne sovjetske namere u cilju preuzimanja kontrole nad jugoslovenskim prostorom i nad Titovim naslednicima.
\end{abstract}

Ključne reči: Jugoslavija, SAD, Sovjetski Savez, Tito, dezintegracija, decentralizacija, raspad

U jednom od brojnih izveštaja američkih zvaničnika, posvećenom burnim unutarpolitičkim zbivanjima u Jugoslaviji, sačinjenom jula 1973, u odeljku „Jugoslavija posle Tita“ izneta je konstatacija „da je Jugoslavija podeljena zemlja, suočena sa krupnim problemima, koji će se po svemu sudeći uvećati kad ostareli i bolesni Tito napusti političku scenu“. Uz iscrpnu dijagnozu svih tegoba sa kojima se jugoslovenski lider suočavao u svojoj 81. godini života („kardiovaskularna arterioskleroza“, „visok krvni pritisak“, „,srčani problemi“", „otežano disanje“), autor ovog izveštaja upozorava da se „Titovi zdravstveni problemi“ ne mogu tretirati isključivo ,kao problemi sa kojim se suočava Jugoslavija, nego kao problemi koji se tiču svih velikih sila, a posebno Sjedinjenih Američkih Država i Sovjetskog Saveza“. Kao ključni argument u prilog ovakvoj konstataciji navodi se „da niko ne može znati kako će ova specifična balkanska država (Jugoslavija - D. B.) izgledati kada jednom nestane ujedinjujuća Titova sila, niti

* Rad je napisan u okviru projekta Srpsko društvo u jugoslovenskoj državi u 20. veku: između demokratije i diktature, (broj 177 016), koji je odobrilo i finansira Ministarstvo prosvete i nauke Republike Srbije. 
može predvideti konkretne okolnosti, koje bi mogle gurnuti ili povući Sovjete da se direktno umešaju“. ${ }^{\prime}$

Gledano iz današnje perspektive, čini se razumljivim to što u izveštajima američkih zvaničnika o situaciji u Jugoslaviji često figuriše deo o raznovrsnim modalitetima eventualnih unutarpolitičkih turbulencija i spoljnopolitičkih implikacija posle smrti neprikosnovenog jugoslovenskog lidera Josipa Broza. S obzirom na to da je Jugoslavija bila jednopartijska država u kojoj je sve značajnije odluke donosio Tito, i u Vašingtonu i u ostalim centrima svetske politike postavljalo se pitanje da li je moguć opstanak jugoslovenske federacije bez njenog autoritarnog lidera. ${ }^{2}$ Takve spekulacije bile su prisutne na Zapadu još tokom 50-ih godina kad god bi se u štampi pojavile vesti o Titovim zdrastvenim teškoćama ili najava njegovog odlaska na odmor $\mathrm{u}$ neku od rezidencija. ${ }^{3}$

Tokom svoje kratkotrajne i uglavnom neuspešne diplomatske misije u Beogradu početkom 60-ih godina, američki ambasador Džordž Kenan (George Kennan) takođe je potcenio Titovu vitalnost i u svojim izveštajima Stejt departmentu razvio čitavu teoriju o mogućoj liberalizaciji i demokratizaciji jugoslovenskog društva posle Titove smrti. To pitanje se posebno aktuelizovalo na prelazu 1962/63. godine, u vreme priprema za donošenje novog jugoslovenskog ustava i intenziviranja sukoba između reformskih i antireformskih snaga u Jugoslaviji. Mada Kenan nije Tita video kao vođu ,centralističke, čvrstorukaške struje“", smatrao je da bi bilo izuzetno pozitivno njegovo povlačenje sa političke scene $\mathrm{u}$ korist mlađih i liberalnijih političara, koji trenutno nisu zauzimali istaknute pozicije u Komunističkoj partiji, ali su, po Kenanu, uživali podršku velikog dela domaćeg građanstva: „Pretežna većina jugoslovenskog društva, a ja mislim i predominantan deo partijskih i vladinih lidera su uvereni da bi bilo poželjno održavati dobre odnose i sa Istokom i sa Zapadom. Mi smo zapravo, blizu potpunom uspehu, osim u slučaju Tita i nekoliko njegovih saradnika; postoji razlog da se nadamo da će proći kratko vreme pre nego što će Tito biti prisiljen, zbog godina i bolesti da odstupi u korist mlađih ljudi koji se rukovode mnogo realističnijim konceptom u vezi stvarnih interesa Jugoslavije“. ${ }^{4}$ Doduše, iako se kasnije pokazalo da je Kenan pogrešno procenio Titovo zdravstveno stanje, bio je u

1 Foreign Relations of the United States, 1969-1976, Volume E-15, Part 1, Documents on Eastern Europe, 1973-1976, Yugoslavia, doc 61.

2 Ljubiša S. Adamović, Džon R. Lempi, Rasel O. Priket, Američko-jugoslovenski ekonomski odnosi posle drugog svetskog rata, Beograd, 1990; Dušan Nikoliš, SAD. Strategija dominacije, Beograd, 1985; Dragan Bogetić, Jugoslovensko-američki odnosi 1961-1971, Beograd, 2012; A. P. Dobson, S. Marsh, US Foreign Policy Since 1945, London, 2000; Josip Moćnik, United States-Yugoslav relations, 1961-80: the twilight of Tito's era and the role of ambassadorial diplomacy in the making of America's Yugoslav policy, Bowling Green, Ohio, 2008; Zvonimir Despot, Tito. Tajne vladara. Najnoviji prilozi za biografiju Josipa Broza, Zagreb, 2009.

3 Dragan Bogetić, Jugoslavija i Zapad, Beograd, 2000.

4 FRUS, 1961-1963 Volume XVI, Eastern Europe, doc 150, Memorandum From the Ambassador to Yugoslavia (Kennan) to Secretary of State Rusk. 
pravu u pogledu reformskih ambicija mlađih ešalona partije. Burna politička previranja u Srbiji i Hrvatskoj početkom 70-ih godina išla su upravo u ovom pravcu.

Ta zbivanja delimično su uticala i na neke neubičajene obrte tokom posete američkog predsednika Ričarda Niksona (Richard Nixon) Jugoslaviji, između 30. septembra i 2. oktobra 1970. Prva poseta jednog američkog predsednika Jugoslaviji, u vreme zaoštravanja vijetnamske i bliskoistočne krize, predstavljala je nesumnjivo događaj koji je privukao pažnju svetske javnosti i postao predmet najrazličitijih spekulacija o motivima dveju strana za organizovanje ovakvog susreta. ${ }^{5}$ Tokom te, relativno kratke, dvodnevne Niksonove posete Jugoslaviji, jedna epizoda, koja se odigrala posle druge runde razgovora dvojice državnika, privukla je posebnu pažnju domaće i svetske javnosti. Radilo se o Niksonovoj poseti Hrvatskoj 1. oktobra i njegovom donekle neuobičajenom nastupu u Zagrebu. Niksonova želja da od svih gradova u Jugoslaviji poseti jedino Zagreb, sama po sebi predstavljala je svojevrsno iznenađenje za jugoslovenske zvaničnike. Ona je izazivala podozrenje, jer je izražena u vreme kada je Jugoslavija bila suočena sa ozbiljnom političkom krizom i kada se sve više osećala opasnost mogućeg raspada države zbog jačanja centrifugalnih tendencija, čije su glavne nosioce mnogi videli upravo u liderima masovnog nacionalnog pokreta u Hrvatskoj. ${ }^{6}$

Da bi otklonio sumnje u pogledu političke pozadine svoje namere da poseti Zagreb, Nikson je, kao gest poštovanja prema Titu, izrazio želju da vidi njegovo rodno mesto Kumrovec. Taj gest je naišao na pozitivan prijem kod Tita, koji je odlučio da mimo ranije utvrđenog programa i sam prati Niksona tokom njegove kratke posete Hrvatskoj.

Ma koliko je Niksonova poseta Zagrebu predstavljala uobičajen gest uvažavanja naroda koji je igrao važnu ulogu u kreiranju spoljne politike zemlje-domaćina, s obzirom na složenu unutrašnju situaciju u Jugoslaviji, ona se odvijala pod budnim okom jugoslovenske vlasti. Posebno podozrenje izazvale su Niksonove reči ,da duh Zagreba, duh Hrvatske, nikada nije uništen i nikada nije porobljen“, „da će Hrvatska uvek živeti“ i na kraju, uzvik izgovoren na jasnom srpskohrvatskom jeziku: ,Živela Hrvatska!“"7 Taj gest američkog predsednika rezultirao je značajnom dozom revolta pojedinih jugoslovenskih političara i okarakterisan je kao mešanje u unutrašnje stvari Jugoslavije i podržavanje nacionalističke frakcije u hrvatskom rukovodstvu. ${ }^{8}$

5 DA MSP RS, 1970, PA, f-170, SAD, 434 736, Zvanična reagovanja u svetu.

6 Niksonova poseta je usledila u vreme kada je u jugoslovenskim političkim krugovima došlo do vidne polarizacije gledišta u vezi sa zaključcima X sednice CK SK Hrvatske održane početkom 1970. Stavovi hrvatskih komunista o daljoj reformi federacije i osude unitarizma izazvali su burna previranja i primljeni su sa znatnim rezervama i osporavanjem u ostalim republikama.

7 DA MSP RS, 1970, PA, f-170, SAD, 434 736, Zvanična reagovanja u svetu; Borba, 2. oktobar 1970.

8 M. Tripalo, $n$. d., str. 179; AJ KPR, I-3-a/SAD, k. 182, Stenografske beleške informacije koju je predsednik SIV-a M. Ribičič podneo o poseti predsednika Niksona Jugoslaviji na Sednici SIV-a 7. oktobra 1970. 
Nešto blažu kvalifikaciju izneo je i Mitja Ribičič, predsednik jugoslovenske vlade, 7. oktobra 1970, na sednici SIV-a posvećenoj poseti predsednika Niksona. Reagujući na komentare u vezi sa Niksonovom posetom Zagrebu, napomenuo je da Amerikanci očigledno dobro poznaju naše unutrašnje odnose, ali „da od toga ne treba praviti neke velike zaključke ili neke velike intrige“. 9 Stav jugoslovenskog ambasadora u Vašingtonu Bogdana Crnobrnje, izložen u izveštaju o jugoslovensko-američkim odnosima za ovaj period, bio je znatno eksplicitniji i instruktivniji. On je ukazivao na to da SAD, kao i svaka imperijalna sila, u političkoj strategiji prema pojedinim državama uvek razmatra sve moguće opcije. Kada je reč o Jugoslaviji, postoje dve opcije koje SAD ima u vidu. Prva opcija, za koju je ova sila naročito zainteresovana, jeste jedinstvena i nezavisna Jugoslavija. Ukoliko bi ta opcija imala izgleda da se ostvari u praksi, ukoliko bi se unutrašnje prilike u Jugoslaviji stabilizovale, vlada SAD-a bi takvoj državi svakako pružila svu moguću političku i ekonomsku podršku. Međutim, ukoliko bi došlo do suprotnog obrta, do dezintegracije Jugoslavije, što se Amerikancima nije činilo nemogućim, onda je ,jasno kao dan da će se aktuelizirati razni kontindžensi planovi (,pomoćni planovi“ - D. B.)“, odnosno „da će biti aktivirana rezervna opcija“. Crnobrnja je, polazeći od svog iskustva iz Vašingtona, upozorio: „Naši unutrašnji događaji su aktuelizirali ustvari nikada potpuno napuštenu opciju 50\%-50\%. Odlazak Niksona u Zagreb i njegov uzvik 'Živela Hrvatska' i 'Živela Jugoslavija', u krajnjoj konsekvenci je praktično značio pokazivanje naglašenog interesa za zapadni deo Jugoslavije“. ${ }^{10}$

U svakom slučaju, epizoda iz Zagreba bila je samo manifestacija sve aktuelnije i sve prisutnije dileme, ,šta će biti s Jugoslavijom posle Tita“ i sama po sebi nije ni u najmanjoj meri umanjila ukupan, neosporno impozantan, politički domašaj Niksonove posete Jugoslaviji. Titu je, s američke strane, obećana neophodna ekonomska i finansijska pomoć, bez koje nije bilo mogućno sanirati tešku ekonomsku situaciju, koja je ozbiljno destabilizovala zemlju spolja i iznutra. Pored toga, Niksonova poseta je doprinela poboljšanju međunarodnog položaja Jugoslavije i jačanju njene bezbednosti. Nikson je bio prvi američki predsednik koji je javno i zvanično potvrdio da SAD prihvata i u potpunosti podržava Jugoslaviju onakvu kakva jeste: nesvrstanu i socijalističku, odnosno da poštuju njeno pravo da samostalno bira put izgradnje svoje unutrašnje i spoljne politike. ${ }^{11}$

9 AJ KPR, I-3-a/SAD, k. 182, Stenografske beleške informacije koju je predsednik SIV-a M. Ribičič podneo o poseti predsednika Niksona Jugoslaviji na Sednici SIV-a 7. oktobra 1970.

10 AJ KPR, I-5-b/SAD, Jugoslovensko-američki odnosi (naglasak na odnose poslednjih deset meseci.)

11 AJ KPR, I-3-a/SAD, k. 182, Zdravica predsednika Sjedinjenih Država na banketu priređenom od strane predsednika Josipa Broza Tita; Zajedničko saopštenje predsednika J. B. Tita i predsednika Ričarda Niksona, (Borba, 3. oktobar 1970) 
Pa, ipak, jugoslovenska ambasada u Vašingtonu oštro je upozoravala vladu SAD-a da nagodbama sa SSSR-om na račun Jugoslavije, a u duhu formule sa Jalte, ${ }^{12}$ dve supersile ugrožavaju nezavisnost Jugoslavije i bezbednost u Evropi. Amerikanci su ovako nešto energično odbacivali uz objašnjenje da se radi o dezinformacijama koje namerno proturaju sovjetske obaveštajne službe i sovjetske diplomate. Po njima, ambasade SSSR-a i istočnoevropskih zemalja u Beogradu namerno forsiraju posebno ,prijateljske“ odnose i veze sa ambasadom SAD-a kako bi kod Jugoslovena ,izazvale podozrenje o šurovanju dve sile na jugoslovenskom terenu“. Rusi „namerno proturaju glasine o navodnom prećutnom dogovoru SSSR i SAD da Zapad investira u jugoslovenskim zapadnim republikama, a Istok u istočnim“. SAD ima informacije da ,predstavnici sovjetske Ambasade obilaze naša preduzeća, koja su u teškoj situaciji, posebno u istočnim delovima zemlje, i nude dopunske, veštački stimulativne poslove."

Složena unutrašnja situacija u Jugoslaviji ozbiljno je destabilizovala njenu međunarodnu poziciju. Tita i njegove saradnike posebno su zabrinjavale glasine o „rezervnim planovima“ Moskve i Vašingtona za slučaj raspada Jugoslavije. U opsežnim analitičkim materijalima jugoslovenskog ministarstva inostranih poslova, sačinjenim tokom priprema za Titovu posetu Vašingtonu (planiranu za kraj oktobra 1971), potvrđeno je postojanje američkih ,rezervnih planova“ za slučaj „cepanja Jugoslavije“. Pažljivo prateći unutrašnju situaciju u Jugoslaviji i razne manifestacije političke i ekonomske krize, američki zvaničnici su preduzimali mere kako eventualni radikalni obrti ,ne bi išli na njihovu štetu“. U tom duhu se objašnjava i relativno tolerantan stav Stejt departmenta prema delovanju ekstremne jugoslovenske emigracije u SAD-u. Iako je takva politika u velikoj meri otežavala saradnju sa Jugoslavijom, Amerikanci nisu bili spremni na bilo kakav zaokret u tom kontekstu, jer nisu želeli da eliminišu ovaj kanal svog upliva u zbivanja u Jugoslaviji koja bi usledila u slučaju njene dezintegracije. ${ }^{14}$ U Beogradu je procenjivano da nestabilne unutrašnje prilike u zemlji moraju u bližoj budućnosti dovesti do intenzivnijeg ispoljavanja aspiracija SAD-a prema pojedinim delovima Jugoslavije. „Neki krugovi u SAD, u poslednje vreme, već povećavaju na političkom i ekonomskom planu pažnju pojedinim sredinama i republikama u Jugoslaviji, što se čini u okviru reagovanja na tekući razvoj u Jugoslaviji, ali može biti i na liniji pothranjivanja teze o zadržavanju opcija (interes za zapadne delove) za slučaj krizne situacije na Balkanu““.15

12 Jugoslovenska strana je uporno prenebregavala opštepoznatu činjenicu da na Jalti takva formula nikad nije usvojena. Podelu interesnih sfera između Zapada i SSSR-a u Jugoslaviji $50 \%-50 \%$ predložio je Čerčil Staljinu tokom njihovog susreta u Moskvi. Tom susretu, inače, nije prisustvovao niko od američkih zvaničnika. (Vinston S. Čerčil, Drugi svetski rat. Tom VI. Trijumf $i$ tragedija, Beograd (bez datuma), str. 207)

13 DA MSP RS, 1970, PA, SAD, f-164, 43028, Telegram ambasade SFRJ u Vašingtonu DSIP-u.

14 AJ KPR, I-3-a/SAD, Američki interes i ciljevi u vezi sa posetom.

15 AJ KPR, I-3-a/SAD, Osnovni elementi platforme naših odnosa sa SAD i razvoj saradnje posle posete Niksona. 
Gotovo istovremeno, u jugoslovenskim krugovima sve se više govori o ispoljavanju interesa sovjetskih rukovodilaca i njihovim pretenzijama prema istočnim delovima Jugoslavije. O tome je govorio i Veljko Mićunović tokom prijema kod Tita pred odlazak u Moskvu radi preuzimanja dužnosti ambasadora u SSSR-u, 4. novembra 1969. Mićunović je skrenuo pažnju Titu na glasine o tome kako zemlje socijalističkog lagera „treba da osvoje ključne pozicije u Srbiji, Makedoniji i Crnoj Gori, da su sada dobri uslovi za to, da su te republike uvijek bile proslovenske, a druga polovina Jugoslavije je prozapadna i nije važno šta će s njom biti“". ${ }^{16}$

Mada je teško utvrditi koliko su pomenuti planovi Vašingtona i Moskve stvarno bili ozbiljno razmatrani kao moguća strategija nastupa u slučaju da dođe do dezintegracije Jugoslavije, oni su u svakom slučaju predstavljali jasan indikator stanja nesigurnosti koja je davala ton sveukupnom političkom životu u Jugoslaviji. Unutrašnja situacija sve se više komplikovala i sama po sebi dovodila u pitanje međunarodni kredibilitet Jugoslavije. Tito se pripremao za radikalne mere radi saniranja političke krize i marginalizovanja svojih političkih oponenata. Sve to, međutim, nije moglo imati željeni efekat bez stabilizovanja međunarodne pozicije Jugoslavije. Da bi se to postiglo neophodno je bilo, pre svega, uspostaviti uravnotežen odnos prema SAD-u i SSSR-u i dokazati obema supersilama da poboljšanje jugoslovenskih odnosa sa jednom stranom nikada neće značiti pogoršanje odnosa sa drugom.

Nastojanja Jugoslavije da zadrži podjednaku distancu prema suprotstavljenim blokovskim grupacijama teško su se mogla realizovati u praksi bez uspostavljanja stabilnih i solidnih odnosa sa Sovjetskim Savezom. U tom kontekstu od posebnog značaja je bila poseta Jugoslaviji lidera sovjetskih komunista Leonida Brežnjeva, krajem septembra 1971, neposredno uoči Titovog odlaska u Vašington. To je bila prva poseta generalnog sekretara KPSS-a posle jugoslovensko-sovjetskog sukoba uslovljenog vojnom intervencijom pet zemalja članica Varšavskog pakta u Čehoslovačkoj, avgusta 1968. Iako su razgovori dveju delegacija u Beogradu povremeno bili na granici konflikta, ipak su na kraju rezultirali epilogom koji je generalno morao imati pozitivno dejstvo na predstojeći susret Tita sa Niksonom. Brežnjevljevo energično odricanje od doktrine ograničenog suvereniteta i Titovo odlučno odbijanje bilo kakvog vida sovjetske pomoći usmerenog na lokalizovanje unutrašnjih jugoslovenskih teškoća opovrgli su spekulacije o nemoći jugoslovenskog rukovodstva da se i dalje samostalno nosi sa aktuelnim političkim izazovima. ${ }^{17} \mathrm{~S}$ druge strane, poruka mira

16 DA MSP RS, 1969, str. pov., f-3, 217, Zabeleška o prijemu i razgovoru (Veljka Mićunovića - D. B.) kod Tita na dan 4. novembra 1969; Veljko Mićunović, Moskovske godine 1969/1971, Beograd, 1984, str. 66.

17 AJ KPR, I-3-a/SSSR, Stenografske beleške sa razgovora Josipa Broza Tita, Predsednika SFRJ i predsednika Saveza komunista Jugoslavije i Leonida Iljiča Brežnjeva, generalnog sekretara Centralnog komiteta Komunističke partije Sovjetskog Saveza, održanih u Beogradu, dana 23. 
koju je Brežnjev preko Tita slao Niksonu i Titova uloga posrednika između lidera dveju supersila, koju je preuzeo tokom razgovora u Beogradu, dodatno su ojačali jugoslovensku pregovaračku poziciju i ugled njenog predsednika u zapadnim političkim krugovima, sklonih da optužuju Tita kako je njegova nesvrstanost „Suviše crvena“. ${ }^{18}$

U svakom slučaju, odlučnost jugoslovenskog rukovodstva na prelazu između 60-ih i 70-ih godina da vodi izbalansiranu politiku između Istoka i Zapada i izbegne „,̌elični zagrljaj“ Kremlja imala je smisla samo u slučaju snažne podrške Zapada. Iako su određeni elementi takve politike promovisani godinu dana ranije, tokom Niksonove posete Jugoslaviji - prevazilaženje krupnih nesporazuma koji su stajali na putu unapređenja bilateralne saradnje i obezbeđivanje garancija $u$ pogledu američke podrške jugoslovenskoj nezavisnosti u velikoj meri zavisili su od ishoda predstojećih razgovora Tita i Niksona u Vašingtonu. Pošto je Tito uspeo da posle susreta sa Brežnjevom obezbedi uslove za poboljšanje odnosa sa Sovjetskim Savezom i socijalističkim lagerom, razgovori sa Niksonom su bili prilika za iniciranje tešnje saradnje sa predvodnikom druge grupacije država. Bez realizacije ove druge komponente jugoslovenske spoljne politike nije bila mogućna ni realizacija proklamovanih premisa jugoslovenske nesvrstanosti.

Sama činjenica da su se Tito i Nikson već sreli godinu dana ranije u Beogradu išla je u prilog postizanju dogovora o ključnim pitanjima odnosa dveju država. Ali, krupne promene koje su se u međuvremenu odigrale u međunarodnim odnosima mogle su potencijalno biti izvor komplikacija u tom kontekstu. Spremnost Sjedinjenih Država da izađu u susret sovjetskoj inicijativi za sazivanje Konferencije o evropskoj bezbednosti na kojoj bi trebalo konačno da se trajno sankcioniše stanje u Evropi uspostavljeno tokom posleratnog razdoblja (posebno nepovredivost postojećih granica) i sklonost dveju supersila da direktnim pregovorima kroje političku kartu sveta izazivala je podozrenje u Beogradu. Mada je Tito zagovarao politiku miroljubive koegzistencije među sukobljenim blokovima i podržavao Niksonovu doktrinu o potrebi da razdoblje konfrontacije ustupi mesto razdoblju pregovora, strahovao je da sve naglašenija uzajamna kooperativnost dveju supersila ne rezultira na kraju njihovim nagodba-

septembra 1971. u 9,00 časova; Isto, Stenografske beleške sa završnih razgovora Predsednika SFRJ i predsednika Saveza komunista Jugoslavije druga Josipa Broza Tita i generalnog sekretara Centralnog komiteta Komunističke partije Sovjetskog Saveza Leonida Iljiča Brežnjeva, vođenih 24. septembra 1971. god u 21,00 časova u Karađorđevu; AJ KPR, I-3-a/SSSR, Zabeleška o neformalnim razgovorima između delegacija SKJ i KPSS prilikom definitivnog usaglašavanja teksta jugoslovensko-sovjetske izjave, koje je izvršeno u noći 24-25. septembra 1971. godine u Karađorđevu; AJ KPR, I-3-a/SSSR, Izlaganje predsednika Tita na proširenoj sednici Izvršnog biroa Predsedništva SKJ, održanoj 3. oktobra 1971. na Brionima.

18 Dragan Bogetić, Jugoslovensko-američki odnosi 1961-1971, Beograd, 2012, str. 314-321; DA MSP RS, 1971, str. pov., f-1, 1109, Komentari svetske štampe povodom posete Leonida Brežnjeva Jugoslaviji. 
ma na račun malih država. Pošto je Jugoslavija i dalje predstavljala nekakvu ,sivu zonu“ za koju se nije znalo tačno da li pripada taboru socijalističkih država, činila se realnom bojazan da će Amerikanci, radi postizanja sovjetskih koncesija oko nekih važnih evropskih i svetskih pitanja, staviti u drugi plan interese Jugoslavije i odustati od dotadašnje strategije podržavanja jugoslovenske nezavisnosti.

Stoga je, pripremajući se za put u Ameriku, Tito pred sebe postavio važan zadatak da ubedi Niksona da će momentalni unutrašnji problemi u zemlji uskoro biti lokalizovani, a politički i ekonomski sistem konsolidovan i da Jugoslavija ostaje važan faktor stabilnosti u Evropi i na Balkanu. Ovaj put jugoslovenski predsednik je bio odlučan u nameri da razjasni odrednice aktuelne jugoslovenske međunarodne strategije i razreši dilemu oko buduće politike SAD-a prema Jugoslaviji. Ako su Niksonova obećanja data godinu dana ranije u Beogradu bila odraz njegovog iskrenog stava o spremnosti američke vlade da odlučno podrži nezavisnost Jugoslavije i njene napore u pravcu razrešenja ekonomske krize, onda američki predsednik ne bi trebalo da se protivi formalizovanju takvog kursa u okviru posebnog zajedničkog jugoslovensko-američkog kominikea, koji je trebalo da obezbedi normiranje načela na kojima bi se zasnivali odnosi dveju država i koji bi predstavljao neku vrstu povelje, koja bi demistifikovala novu platformu odnosa Jugoslavije sa blokom zapadnih država. ${ }^{19}$ Ako je Hruščov prihvatio takvu jugoslovensku inicijativu u Beogradu 1955, nije bilo razloga da Nikson tako nešto odbije te, 1971. godine.

Ovakvo rezonovanje pokazalo se opravdano. Razgovori Tita i Niksona završeni su usvajanjem Zajedničkog saopštenja u kome su precizno formulisani principi i načela na kojima će se ubuduće zasnivati jugoslovensko-američki odnosi. Potvrđen je ,interes SAD za nezavisnu i nesvrstanu poziciju i politiku Jugoslavije“ i naglašeno ,da je politika nesvrstavanja Jugoslavije značajan faktor u međunarodnim odnosima“. U tom smislu ,zemlje koje sprovode takvu politiku, zajedno sa ostalim svetom, mogu pružiti aktivan doprinos razrešavanju svetskih problema i povoljnim tokovima međunarodnih odnosa“. U kominikeu su precizno navedena načela za čiju će se univerzalnu primenu u međunarodnim odnosima zalagati vlade SAD-a i Jugoslavije: ,poštovanje nacionalne nezavisnosti i državnog suvereniteta“, ,nedeljivost mira i međuzavisnosti“, ,pregovaranje uz uvažavanje interesa svih zemalja, velikih i malih“, ,puna ravnopravnost država bez obzira na razlike ili sličnosti u njihovim društveno-poltičkim sistemima, u punoj saglasnosti sa duhom i principima Povelje Ujedinjenih nacija“. U skladu sa opaskom izrečenom tokom razgovora dvojice predsednika „da zgrada mira ne može izdržati ako sve nacije ne učestvuju u njenoj izgradnji i ako sve u tome ne sagledaju i svoje sopstvene interese " i u skladu sa Titovim nastojanjem da predstojeća Konferencija o evropskoj bezbednosti ne sme da bude skup na kome

19 AJ KPR, I-2/SAD, Politički aspekti odnosa. Kominike; Isto. Unutrašnji razvoj i spoljnopolitička aktivnost SAD i SFRJ i njihovo dejstvo na međusobne pozicije i odnose. 
će velike sile praviti nagodbe na račun sudbine malih država, u Zajedničkom saopštenju potvrđen je stav ,da su čvrst mir i stvarna bezbednost neodvojivi i da se mogu postići samo ako obuhvate Evropu u celini, a ne samo jedan ili drugi njen deo“. Dvojica predsednika su izrazila svoje uverenje „da je neophodna uloga svake evropske i drugih zainteresovanih država u izgradnji jedne Evrope u kojoj su popuštanje, mir i bezbednost u punoj meri osigurani za sve njene narode“". ${ }^{20}$

Sama činjenica da su ovu vrstu dokumenta, koja ima trajniji, širi i dugoročniji karakter, američki predsednici retko potpisivali, govori o tome kolika je bila „politička težina“ Kominikea. Sve je ukazivalo na to da je stepen uzajamnog poverenja dvojice predsednika znatno porastao posle razgovora $u$ Vašingtonu.

Međutim, pravi razlog koji je doveo do ovakvog obrta teško je otkriti pukom analizom samih zabeleški o razgovorima, a još manje na osnovu analize zvaničnog Titovog i Niksonovog obraćanja javnosti. Naime, najinteresantnije i najznačajnije scene vezane za Titovu posetu SAD-u odigravale su se mimo zvaničnih razgovora dveju strana, tokom svečane večere koju je Nikson priredio u Titovu čast u Beloj kući, 28. oktobra. Tom prilikom, Tito i jugoslovenski ministar inostranih poslova Mirko Tepavac na jedan vrlo neobičan i neuobičajen način poslali su alarmantnu, mada i pomalo nejasnu poruku svojim domaćinima, u kojoj im skreću pažnju da ozbiljno strahuju od sovjetske intervencije u slučaju političkih nemira u Jugoslaviji.

Smisao te poruke se mogao razumeti jedino na osnovu uspostavljanja adekvatne korelacije između onoga što je Tepavac na svečanoj večeri u poverenju izložio državnom sekretaru Vilijemu Rodžersu (William Rogers) i onoga što je potom izložio Niksonu. Rodžers je objasnio Niksonu da ga je u jednom trenutku Tepavac diskretno povukao u stranu i skrenuo mu pažnju da ima samo nekoliko minuta da mu saopšti nešto važno. Mada je slabo govorio engleski, zbog poverljivosti poruke Tepavac nipošto nije želeo prisustvo prevodioca. Rodžers se zbunio kada se ovaj konačno izjasnio: „Želim da znate, ovo je samo za Vaše uši - susret sa Brežnjevom nije protekao dobro. Vi treba to da znate. Vi ste jedini kome sam to rekao". Na Rodžersovu primedbu da on to mora preneti predsedniku Niksonu, Tepavac je odgovorio da je to u redu i da mu je Tito upravo rekao da saopšti to njemu, kako bi on to posle preneo Niksonu. ${ }^{21}$

O čemu se ovde zapravo radilo i zašto je Tito tokom zvaničnih razgovora sa Niksonom pozitivno govorio o svom susretu sa Brežnjevom, dvojica američkih zvaničnika su razjasnila tek kada su poverljiv razgovor Tepavca i Rodžersa povezala sa pomalo nejasnom porukom koju je Tepavac poslao Niksonu tokom razgovora koji je odmah potom usledio. S obzirom na to da je sada bio prisutan

20 AJ KPR, I-2/SAD, Jugoslovensko-američka zajednička izjava.

${ }^{21}$ FRUS, 1969-1976, Volume XXIX, Eastern Europe; Eastern Mediterranean, 1969-1972, doc 233, Editorial Note. 
i prevodilac, Tepavac nije smeo da bude eksplicitan, ali se trudio da ipak bude, koliko je god to moguće, konkretniji. Iako je skoro celo veče bio u društvu Niksona, i njemu se obratio uz frazu ,da ima samo nekoliko minuta za razgovor“. Tada je upozorio: „Mi u Jugoslaviji ćemo se možda suočiti sa velikim problemima. Predsednik Tito je veoma star i kada on umre, kada ode, mislim, kada se povuče, tada ćemo se suočiti sa pokušajima nekih od naših suseda da iskoriste tu činjenicu“. Pošto je sve ovo Niksonu bilo preneto preko prevodioca (Tepavac sada nije govorio na engleskom), jugoslovenski ministar je u uvijenoj formi poručio da radi očuvanja svoje nezavisnosti Jugoslavija očekuje od SAD-a „da iskoriste sav svoj uticaj da drugi drže ruke dalje od Jugoslavije“. Kada je Nikson obećao da će njegova zemlja postupiti upravo tako, Tepavac je zadovoljno prokomentarisao: „Primili ste poruku“.22

Povezujući ova dva razgovora koje je Tepavac vodio sa njima, Nikson i Rodžers su izvukli zaključak da su Jugosloveni „smrtno preplašeni“ (,scared to death"), „da se plaše Rusa" (,they fear the Russians") i da se ono što Tito govori javno može objasniti upravo time što se „Tito plaši od Rusa da kaže šta misli“" (,Tito is afraid to say what he thinks of the Russians"). Stoga je Tito poslao Tepavca da prenese njegovu poruku. U tom smislu, po Niksonu, u slučaju da do Rusa dođe informacija o svemu ovome, Tito je mogao da se brani da on lično ništa nije rekao od toga. Doduše, Tito nije do kraja ostao u pozadini svega. Nikson je obavestio Rodžersa da mu se Tito kasnije obratio bez prevodioca i da mu je rekao: „Ministar inostranih poslova me je obavestio o svojim razgovorima sa Vama i mi se sada osećamo mnogo bolje“. Inače, i Nikson i Rodžers su shvatili da Tito nema poverenja u prevoditeljku (da sumnja da ona o svemu obaveštava Sovjete) i da je, pored ostaloga, i zbog toga bila neophodna ovako komplikovana komunikacija. ${ }^{23}$

Shvatajući Titovu poziciju, Nikson i Rodžers su se dogovorili da tokom druge runde jugoslovensko-američkih razgovora ne pominju ništa što se ticalo ove važne epizode, koja je sama po sebi u potpunosti razjasnila sve ono što su jugoslovenski zvaničnici želeli da kažu domaćinima u pogledu svojih očekivanja od SAD-a i u vezi sa zajedničkom porukom svetu koju iz Vašingtona treba odaslati na kraju pregovora u okviru posebnog kominikea. ${ }^{24}$

O tome koliko su Tito i njegovi saradnici strahovali od sovjetske intervencije moglo se videti i iz razgovora koji su na ovu temu, u najvećoj tajnosti, vođeni tokom 1972. i 1973. godine između jugoslovenskih zvaničnika i novog američkog ambasadora Malkolma Tuna (Malcolm Toon). Tu je posebno indikativan razgovor američkog ambasadora sa Stanetom Dolancom, sekretarom Izvršnog komiteta CK SKJ, koga su Amerikanci sve češće pominjali kao Titovog

\footnotetext{
22 Isto.

23 Isto.

${ }^{24}$ Isto.
} 
naslednika. ${ }^{25} \mathrm{O}$ prvom susretu sa Dolancom Tun je izvestio svoju vladu u telegramu od 20. maja 1972. Tokom tog razgovora, uz konstataciju „da su Sjedinjene Države samo osudile napad na Čehoslovačku i nisu ništa drugo učinile u vezi s tim“, Dolanc je otvoreno postavio pitanje američkom ambasadoru šta bi Sjedinjene Američke Države učinile ukoliko bi SSSR napao neku državu koja nije članica Varšavskog pakta. Tun je odgovorio ,da bi na tu vrstu reakcije uticao čitav niz faktora (pored ostaloga: koja je konkretno država napadnuta, pod kakvim okolnostima je izvršena invazija, da li je narod te zemlje odlučan da se brani, kakav je stav američke javnosti i Kongresa) i da zbog svega toga nije mogućno dati konkretan odgovor na ovako složeno pitanje“. Dolanc je izrazio svoje nerazumevanje u vezi ovakvog odgovora i naglo prešao na drugu temu. ${ }^{26}$

Komentarišući ovakav nastup Dolanca i opštu situaciju u Jugoslaviji, Tun je ukazao na „vrlo snažne centrifugalne sile u toj zemlji““ i strah jugoslovenskog rukovodstva da će SSSR iskoristiti tu okolnost kao povod za intervenciju i političko uplitanje. Američki ambasador je naveo da su se na sličan način i sa sličnim pitanjem kao i Dolanc Amerikancima obraćali i drugi jugoslovenski zvaničnici i diplomate (u januaru 1972. ministar inostranih poslova Mirko Tepavac, a početkom februara zamenik ministra inostranih poslova Jakša Petrić i predstavnik spoljnopolitičkog odbora Savezne skupštine Bogdan Osolnik). Tito je tada imao 81 godinu i očekivalo se da će uskoro napustiti političku scenu, što je samo po sebi otvaralo mnoga sudbonosna pitanja. Po Tunu, glavne dileme sa kojima su se suočavali jugoslovenski zvaničnici ticale su se epiloga unutrašnjih političkih previranja i moguće nagodbe velikih sila na račun Jugoslavije. Kada je reč o ovom prvom kompleksu problema, on se, zapravo, svodio na pitanje: da li uopšte postoji neka ličnost ili snaga koja će posle Titove smrti moći da spase Jugoslaviju od dalje dezintegracije i raspada. Tun je smatrao da je jedina snaga koja će tokom eskalacije krize u Jugoslaviji moći da zaštiti njen teritorijalni integritet i jedinstvo - jugoslovenska armija, koja je sačuvala unutrašnju disciplinu i koheziju i koja ima bliske veze sa državnim bezbedonosnim službama. Što se, pak, tiče straha jugoslovenskih političara od mogućnosti da Amerikanci prepuste Jugoslaviju Sovjetskom Savezu, Tun je smatrao da bi po tom pitanju iz Vašingtona trebalo eksplicitnije dati na znanje Beogradu da takva opcija ne postoji i da će SAD i ubuduće podržavati jugoslovensku nezavisnost i njenu politiku nesvrstavanja. ${ }^{27}$

25 Amerikanci su smatrali da Tito posebno ceni Dolanca, jer on uživa veliki ugled i u Partiji i u vojnim krugovima, a pruža bezrezervnu podršku snagama koje se bore protiv dezintegracije Jugoslavije. Posebno pozitivna Dolančeva referenca u tom sklopu je bila što „iako je Slovenac, nije etnički neprihvatljiv ostalim nacijama“. FRUS, 1969-1976, Volume E-15, Part 1, Documents on Eastern Europe, 1973-1976, Yugoslavia, doc 61)

26 FRUS, 1969-1976, Volume XXIX, Eastern Europe; Eastern Mediterranean, 1969-1972, doc. 236, Telegram From the Embassy in Yugoslavia to the Department of State, Belgrade, April 20, 1972.

27 Isto. 
Procena američke Centralne obaveštajne agencije (CIA), u izveštaju od 5. jula 1973, bila je „da čak i bez Tita postoje dobre šanse za opstanak jugoslovenske federacije i njenog hibridnog, nesovjetskog oblika socijalizma. U toku su upečatljivi napori da se reguliše pitanje nasleđivanja Tita, da se Stane Dolanc nametne kao potencijalni naslednik i da se jugoslovenska komunistička partija iz faze opadanja transformiše u efikasnu nacionalnu snagu... Vodeći partijski lideri, verovatno funkcionišući pod Dolancom kao sekretarom Izvršnog biroa (praktično Politbiroa), u početku bi preferirali da se suoče sa izazovima posttitovskog perioda. Vodeći savezni funkcioneri bez sumnje bi osećali isto; oni ne bi bili u položaju da uruše vlast. Glavni republički lideri, od kojih niko za sad ne predstavlja militantne interese nacija takođe bi učestvovali u saveznim telima. To bi barem za izvesno vreme obuzdalo one među njima koji bi bili skloni forsiranju republičke linije. Nezadovoljni članovi partije - na primer oni koji su smenjeni u hrvatskom nacionalnom buđenju i oni koji zahtevaju demokratizaciju državnog života - verovatno ne bi bili sposobni da se nametnu kao jedinstvena opoziciona snaga dosta vremena posle Titovog odlaska, ako bi se to ikad i ostvarilo". ${ }^{28}$

Zaključeno je „da direktna sovjetska intervencija u Jugoslaviji posle Tita nije verovatna. Moskvi nedostaje značajna podrška u jugoslovenskom društvu, svesna je da bi jaki pritisci na Beograd verovatno samo gurnuli zemlju još više ka Zapadu i ne smatra obnovu sovjetske dominacije nad Jugoslavijom svojim vitalnim interesom. Čak i u slučaju ozbiljnih nemira u Jugoslaviji - sve dok opstaje politika detanta sa Zapadom - Moskva bi se više trudila da izoluje taj problem, nego da se direktno u njega umeša. Naposletku, cene i rizici sovjetske vojne intervencije protiv Jugoslavije bili bi visoki, a ulozi nesamerljivi“.

$\mathrm{Pa}$, ipak, u istom izveštaju je napomenuto „da se ove ocene ne mogu izneti bez rezervi, jer se mogućnosti previranja posle Tita i opasnosti od posledične sovjetske intervencije ne mogu zanemariti... Da li će jugoslovenski eksperiment preživeti bez njega - da li jugoslovenska država može preživeti kao jedinstven entitet bez njegovog vođstva - postaje realno pitanje“. U slučaju da, ipak dođe do dezintegracije Jugoslavije, u analitičkim odeljenjima CIA-e skiciran je sledeći scenario: „Pojedine ili sve republike bi se otcepile. Neke bi se (na primer Hrvatska) okrenule Zapadu za pomoć, a druge bi ostale nesvrstane. Ostaci savezne vlasti i većina visokih vojnih rukovodilaca nastojali bi da povrate federaciju, ako treba i silom, uz podršku pojedinih republičkih vlada (na primer Srbije). Pretio bi građanski rat, a prozapadne republike bi apelovale za pomoć SAD i NATO-a, dok bi Srbija možda zatražila direktnu sovjetsku pomoć. Reakcije Moskve na takvu situaciju bile bi pomešane i postale bi predmet ozbiljne debate“".29

${ }^{28}$ FRUS, 1969-1976, Volume E-15, Part 1, Documents on Eastern Europe, 1973-1976, Yugoslavia, doc 61 .

29 U izveštaju se ukazuje na to da bi sovjetsko rukovodstvo najverovatnije donelo odluku da interveniše u Jugoslaviji ukoliko bi: ,a) sovjetska politika detanta već bila napuštena; b) ukoliko 
Eventualna sovjetska intervencija u Jugoslaviji ocenjena je kao akt koji bi ozbiljno poremetio stabilnost Evrope i sveta i u tom smislu ona za većinu zapadnoevropskih zemalja ,ne bi bila ono što je sovjetska intervencija predstavljala u Čehoslovačkoj: nesrećan ali suštinski defanzivan pokret Moskve da zaštiti svoje interese u okviru bloka. Naprotiv, bila bi to nepotrebna i provokativna ofanziva na teritoriju van bloka, preduzeta više da bi se proširila sovjetska moć, a ne da bi se očuvala“. Pošto zapadnoevropske zemlje ne bi na sovjetsku pretnju mogle da efikasno odgovore bez punog učešća SAD-a - konkretan nastup ove sile bi istovremeno predstavljao ,test privrženosti SAD evropskoj bezbednosti“. Ukoliko bi se tu sve zapadne sile postavile jedinstveno i energično istakle da svoj vitalni interes vide u očuvanju nezavisnosti i teritorijalnog integriteta Jugoslavije, „Sovjeti bi verovatno zaključili da bi rizik bio prevelik u odnosu na bilo kakve efekte koje mogu da ostvare u Jugoslaviji“‘.30

U Vašingtonu su procenjivali da će tokom posttitovske ere glavni garant daljeg očuvanja teritorijalne celovitosti i unutrašnje kohezije Jugoslavije biti - njena armija. Doduše, tu stabilizujuću i pozitivnu ulogu jugoslovenska armija uspešno, zajedno sa Titom, ostvaruje i u sadašnjem periodu (u uslovima oštrog međunacionalnog sukobljavanja), ali će ona biti posebno naglašena posle Titove smrti. ${ }^{31}$ Budući da će od ostvarenog nivoa vojne saradnje SAD i Jugoslavije zavisiti i odnosi ovih država tokom posttitovske ere, pred Stejt departmentom je bio zadatak da preduzme odgovarajuće korake kako bi se nezadovoljavajuće stanje u toj sferi poboljšalo. „Američka armija je imala veliki uticaj i direktne kontakte sa jugoslovenskom vojskom od 1951. do 1957, tokom perioda Programa američke vojne pomoći. Međutim, uporedo sa prekidom kontinuiteta našeg Programa vojne pomoći Jugoslaviji, uticaj i kontakti su prekinuti. Od tada naši direktni kontakti sa jugoslovenskom armijom su minimalni. Posle invazije u Čehoslovačkoj, jugoslovenski zvaničnici i vojni funkcioneri ponovo su počeli da se obraćaju Zapadu za pomoć... Od vitalnog je značaja sada, kada se približavamo kraju Titove ere, da povratimo njihovo poverenje i razvijemo posebne veze i kanale koji bi koristili nacionalnim interesima SAD. Tito je možda daleko od toga da dozvoli potpuni razvoj ovih odnosa, ali tokom posttitovskog razdoblja će za ovako nešto biti prekasno". 32

Zapad ne bi izgledao spreman da odgovori silom; c) ukoliko bi izgledalo da bi neki poremećaj u Jugoslaviji mogao dovesti do nereda u drugim istočnoevropskim zemljama“. FRUS, 1969-1976, Volume E-15, Part 1, Documents on Eastern Europe, 1973-1976, Yugoslavia, doc 61)

30 Isto.

31 FRUS, 1969-1976, Volume E-15, Part 1, Documents on Eastern Europe, 1973-1976, Yugoslavia, doc. 59, Memorandum From the Chairman of the National Security Council Under Secretaires Committee (Rush) to President Nixon, Washington, May 18, 1973; Isto, doc 62, Airgram A-385 From the Embassy in Yugoslavia to the Department of State; Isto, doc 67, Memorandum of Conversation, Washington, February 15, 1974.

32 Isto, doc 60, Interdepartment Policy Paper Prepared by the Departments of State and Defense, Washington, undated. 
U duhu ovakvih preporuka, početkom 70-ih, Amerikanci traže način kako da makar delimično preuzmu od Sovjetskog Saveza ulogu snabdevača Jugoslavije sofisticiranom vojnom opremom. Organizuju se sve učestalije razmene poseta vojnih funkcionera Jugoslavije i SAD-a i postepeno se stvaraju normativni uslovi za intenziviranje bilateralne vojne saradnje. Prva vojna delegacija Jugoslavije posetila je SAD septembra 1971. Nju je predvodio general Veljko Kadijević. Potom je, usledila poseta generala Ivana Dolničara Sjedinjenim Državama, maja 1972. i poseta Jugoslaviji američke delegacije predvođene zamenikom Štaba za vojne operacije generalom E. Robertsom, novembra 1972. Tokom ovih razgovora Jugosloveni su tražili od vlade SAD-a da im pomogne da izgrade sopstvenu vojnu industriju i obezbede uslove za osamostaljivanje od svog dotadašnjeg ključnog vojno-strateškog partnera - Sovjetskog Saveza. Takvi zahtevi činili su se američkim pregovaračima megalomanski i inkompatibilni sa vojno-strateškim interesima SAD-a. Ono na šta je američka vlada bila spremna, to su bile isporuke vojnog materijala i sofisticirane tehnologije, koja bi se servisirala u zapadnim radionicama. Pa, ipak, nekakav kompromis (bliži američkom stanovištu) je postignut. U tom smislu, pošto su ovi razgovori doprineli postizanju načelnog sporazuma o budućim modalitetima jugoslovensko-američke vojne saradnje i raspoloživim vrstama vojnog materijala neophodnog za jačanje borbene gotovosti jugoslovenske armije, vojna pitanja sve češće se nameću kao važne teme diplomatskih kontakata predstavnika dveju država. ${ }^{33}$

Međutim, iako su američki zvaničnici u jugoslovenskoj armiji videli važan kohezioni faktor „koji unosi stabilnost u nestabilnu situaciju“ - nisu bili skloni precenjivanju njene uloge u otklanjanju unutrašnjih pretnji opstanku jugoslovenske federacije. ,Jugoslovenska vojska nije politički monolitna, tako da bi politički demarš ili udar skoro sigurno produbio njenu unutrašnju podelu. Svaka dalja ekspanzija političke uloge vojske otuđila bi Hrvate, Slovence, Albance i ostale nesrbe. Iako je režim pokušao da umanji istorijsku srpsku dominaciju u oficirskom koru, nesrbi i dalje gledaju na vojsku kao predominantno srpsku instituciju sa centralističkim usmerenjem, koja preti njihovim nacionalnim interesima i identitetima. Mada bi vojna intervencija privremeno stabilizovala kriznu situaciju, dugoročne mogućnosti bi i dalje bile: potencijalna nestabilnost i nemiri uz koje ne treba isključiti ni opciju građanskog rata". ${ }^{34}$

Prvu studiju u kojoj se ozbiljno računa na raspad Jugoslavije, Sjedinjene Države su dovršile tek decembra 1976. S obzirom na to da u ovo vreme decentralizacija sistema sve više poprima formu dezintegracije, očigledno nije bilo nikakvih dilema oko formulacije naslova - „Jugoslavija: napetosti na vrhu“.

33 Isto.

34 The Nacional Archives and Records Administration. Office of Strategic Services. (Momčilo Pavlović, Dokumenta CIA o Jugoslaviji 1948-1983. Šanse Jugoslavije posle Tita, Beograd, 2009, str. 267-268) 
Posebno mesto, po običaju, posvećeno je Titovom zdravlju i mentalnom stanju: „Dok je Tito bio dobrog zdravlja, nije bilo sumnje ko je vrhovni autoritet u Jugoslaviji. Psihičko i fizičko propadanje poslednjih godina i delimično prenošenje vlasti na niže nivoe, doveli su do toga, da se taj autoritet donekle rasplinuo. Utisak je da se odluke često donose zavisno od trenutka, da su često kontradiktorne $\mathrm{i}$ uveliko oblikovane sukobima pojedinačnih interesa." ${ }^{\text {"35 }}$

U Vašingtonu su procenjivali da ,uprkos relativnom miru, kada je reč o nacionalnom pitanju, od tzv. hrvatske krize, percepcije i strasti koje su potpalile ove nacionalne izlive nisu nestale“. Činilo im se očiglednim „da će Titovim odlaskom režim izgubiti najveći deo zaštite koji je uživao kao rezultat njegove nedodirljive reputacije i etničke nepristrasnosti“. Naime, niko od njegovih mogućih naslednika nije imao takvu reputaciju. Sve ovo navodilo je na zaključak „da nijedan stepen zapadne politike ne može zaustaviti Titove naslednike od upuštanja u samouništavajuću borbu za nasleđe ili zaustaviti jugoslovenske konstitutivne narode od građanskog rata, ako oni tako hoće. Međutim, vešto tempirana i pažljivo osmišljena i orkestrirana zapadna podrška mogla bi doprineti konsolidaciji i preživljavanju potencijalno održivog posttitovskog rukovodstva i time očuvati stabilan regionalan, kontinentalan i globalan odnos snaga ${ }^{36}$ Prvi deo zaključka su kasnija zbivanja uglavnom verifikovala. Drugi deo, pak, na sreću jednog dela jugoslovenske populacije, a na nesreću drugog - pokazao se kao nerealna politička fikcija, uslovljena nepoznavanjem pravog stanja stvari.

\section{Summary}

Dr Dragan Bogetić

\section{The Early 1970s American Perception of Yugoslavia after Tito's Death}

Key words: Yugoslavia, USA, Soviet Union, Tito, disintegration, decentralization, break-up

Washington and other centers of world politics in late 1960s and early 1970s increasingly dealt with the fate of Yugoslavia after Tito's death and the question if the survival of the Yugoslav federation was possible at all without him. Since Yugoslavia was a one-party state where all more important decisions

35 FRUS, 1969-1976, Volume E-15, Part 1, Documents on Eastern Europe, 1973-1976, Yugoslavia, doc. 83, Memorandum Prepared in the Central Intelligence Agency's Office of Current Intelligence, Washington, December 10, 1976.

36 The Nacional Archives and Records Administration. Office of Strategic Services. (Momčilo Pavlović, $n$. $d$., str. 265 i 270). 
were reached by Tito, and since the Yugoslav leader was pushing 80, such dilemmas seemed justified. The more so since inter-ethnic tensions in Yugoslavia were escalating and nationalist aspirations and separatist tendencies were becoming increasingly more pronounced. The stability of the Yugoslav international position was particularly jeopardized by serious economic problems stemming from the unsuccessful economic reform and disintegrated market.

After turbulent events in Croatia in spring 1971 and the deposition of the Croat leadership, and the subsequent reckoning with liberal Serbian politicians in 1972, American officials started designing the adequate international strategy to be applied in case of serious internal unrest in that country or in the case of its threatening disintegration. They thought that Tito's eventual step-down from the political scene would surely be a kind of touchstone for such processes and that it would additionally complicate them. It was estimated in Washington that the USSR would very probably use the internal unrest in Yugoslavia as an excuse for a military intervention in the spirit of the principle of ,socialist internationalism" and the Brezhnev doctrine on the duty of socialist block to intervene in the countries where socialism was in danger.

The problem in developing an optimal American strategy was that it wasn't possible to predict with certainty what the final issue of internal unrest in Yugoslavia after Tito's death would be and what the reaction of the official Moscow would be. Therefore numerous overall political strategies were designed that were supposed to be an adequate response to possible turns in that context. To be sure, no-one could foresee at that time that the moment of the break-up of Yugoslavia would overlap with the moment of the break-up of the USSR whose political aspirations Tito's successors and American officials so feared. 